\title{
Astigmatism correction in cataract surgery with Rayner toric intraocular lenses
}

This article was published in the following Dove Press journal:

Clinical Optometry

4 September 2010

Number of times this article has been viewed

\section{Sally L Painter \\ Kikkeri S Arun \\ Jonathan K Kam \\ CK Patel}

Oxford Eye Hospital, John Radcliffe Hospital, Headley Way, Headington, Oxford, United Kingdom
Correspondence: Sally L Painter Oxford Eye Hospital, John Radcliffe Hospital, Headley Way, Headington, Oxford, OX3 9DU, United Kingdom Tel +44- I 865-234800

Fax +44-1865-234800

Email sallylpainter@gmail.com
Background: Cataract surgery is increasingly regarded as a refractive procedure. Corneal astigmatism can be reduced by the insertion of a toric intraocular lens (T-IOL). Rayner T-flex T-IOLs are licensed for the correction of astigmatism.

Methods: In this retrospective study, 46 eyes from 34 patients, in whom T-IOLs were inserted, have been examined. Astigmatism was analyzed using power vectors.

Results: Postoperatively, $72 \%$ had unaided vision of $6 / 9$ or better, with $42 \%$ having $<0.25$ diopters (D) of residual cylinder and $78 \%$ having $<1.5 \mathrm{D}$ of residual cylinder, compared with $6.9 \%$ preoperatively. Once astigmatism had been converted to power vectors, $J_{0}$ (measure of astigmatism with an axis of $0^{\circ}$ ) reduced in magnitude from $-0.81 \mathrm{D} \pm 0.85$ to $0.09 \mathrm{D} \pm 0.42$ $(P<0.001)$.

Conclusion: Rayner T-flex lenses can be reliably used to correct corneal astigmatism.

Keywords: Toric intraocular lens, cataract surgery, astigmatism

\section{Introduction}

Visually significant astigmatism affects approximately $15 \%$ of all patients undergoing cataract surgery. ${ }^{1}$ Refractive astigmatism is determined by corneal and lenticular components. Cataract surgery removes lenticular astigmatism but may unmask corneal astigmatism. Incisions used for phacoemulsification induce less astigmatism as incision sizes decrease. ${ }^{2,3}$ Neutralization of corneal astigmatism during phacoemulsification allows these patients the opportunity for relative spectacle independence, which is the overall aim of refractive cataract surgery. When monofocal lenses are used, this independence is limited to a fixed focal length; however, the advent of multifocal toric lenses may, in the future, give complete spectacle independence. The current surgical treatment options for astigmatism include placement of the main phacoemulsification wound on-axis, refractive keratotomy, and toric intraocular lenses (T-IOLs).

Relaxing incisions at the limbus, although reliable, are only effective in patients with $<1.5$ diopters (D) of corneal astigmatism. ${ }^{4}$ Although incisional keratotomy can correct $>1.5 \mathrm{D}$, if incisions are closer to the visual axis, its effect is variable and unpredictable. T-IOLs have the potential for increased predictability provided they are placed accurately and do not rotate postoperatively. 5,6

Now, there are many T-IOLs on the market. Rayner T-flex ${ }^{\mathrm{TM}}$ T-IOLs (Rayner; Hove, England) are, at the time of writing, licensed for use in Europe in patients with corneal astigmatism. They are hydrophilic acrylic lenses in a single-piece plate-haptic design. The lenses have maximal rotational stability due to a unique mechanism of compression of the haptics within the capsule. As postoperative capsular contraction occurs, the 
haptics are gradually compressed until the haptic edge meets the optic. The lens then becomes oval in shape, preventing rotation and minimizing vaulting. The square-edge design of the haptic-optic junction prevents epithelial growth of the capsule and therefore minimizes posterior capsular opacification. The lens is designed in 2 optical diameters: $573 \mathrm{~T}$ with an optic of $5.75 \mathrm{~mm}$, designed for higher powered lenses, and $623 \mathrm{~T}$ with an optic of $6.25 \mathrm{~mm}$, designed for lower and medium powered lenses. Spherical powers range from -10 to $+35 \mathrm{D}$ with up to $+11 \mathrm{D}$ of cylinder in $0.25 \mathrm{D}$ intervals. Lenses are chosen using an online calculator, Raytrace, after entering keratometric data to infer corneal astigmatism and desired refractive outcome. The lens can be injected via a single-use injector through a $3 \mathrm{~mm}$ wound and has linear marks on its anterior surface to allow correct surgical alignment (Figure 1).

The purpose of this study was to audit the use of Rayner T-IOLs in the setting of a large teaching hospital for clinical practice. To date, no published data are available on the use of Rayner T-IOL. Therefore, the data published by Alcon (Alcon, Fort Worth, TX, USA) for the licensing of their Acrysof ${ }^{\circledR}$ T-IOL (Alcon) with the US Food and Drug Administration were used to compare evaluation strategies and results. ${ }^{7}$

\section{Methods}

Patients with a keratometric cylinder $>0.75 \mathrm{D}$, attending for cataract surgery under the care of one of the authors (CK Patel [CKP]), were offered T-IOLs. Consecutive patients who had a Rayner T-flex IOL inserted between 2006 and 2008 were initially evaluated in this retrospective study, whereas patients who previously had corneal surgery, irregular astigmatism, or keratoconus were excluded in order to reduce

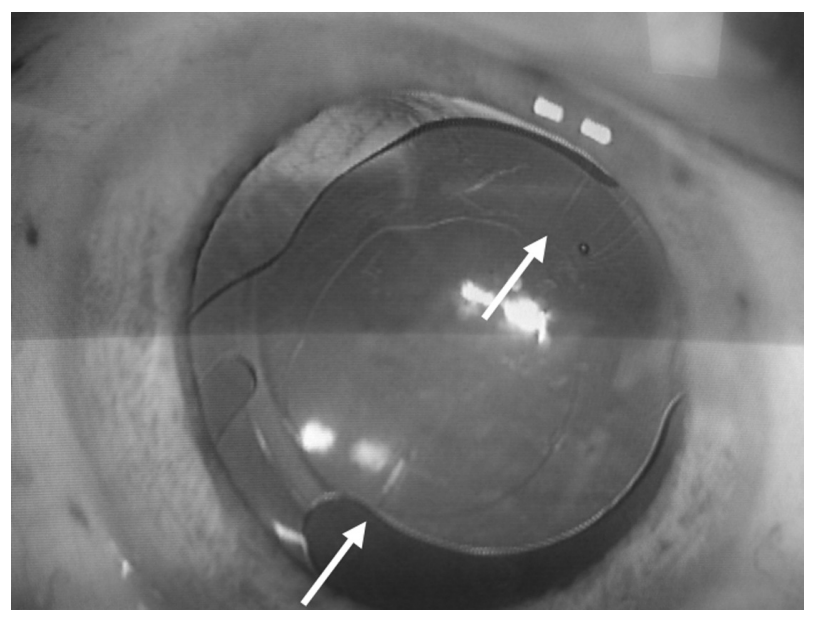

Figure I Rayner toric intraocular lens in situ with arrows showing markers for axis alignment. outlier bias. Although Rayner T-IOLs are licensed for use in patients with irregular astigmatism and keratoconus, their use is not evidence based. A total of 65 eyes had Rayner T-IOLs inserted, but refractive outcomes were complete in only 46 eyes, all of whom were included in the study.

Preoperatively, best corrected visual acuities were recorded, and a subjective refraction was documented. Keratometry was performed by IOL Master (IOL Master V5.2.1; Carl Zeiss, Germany). Keratometric data and refractive outcome were entered into the Rayner Toric calculator, and chosen lenses neutralized both sphere and cylinder to achieve a spherical equivalent as close to zero as possible. The Toric calculator supplies the appropriate optic diameter for the sphere and cylinder combination and details the correct axis of alignment.

Preoperatively, the eye was marked in the anesthetic room, with the patient sitting up straight with his or her head in a neutral position. The vertical meridian was marked with ink at the 6 and 12 o'clock positions on the corneal side of the limbus. Intraoperatively, a Mendez gauge (Malosa Medical, Elland, England) was used to mark the axis of alignment of the lens. The patient then underwent standard divide and conquer phacoemulsification under a sub-Tenon's anesthetic with a $2.75-\mathrm{mm}$ corneal incision placed at $120^{\circ}$. No specific attempt was made to use on-axis incisions. The wound was extended to $3.0 \mathrm{~mm}$ to inject the T-IOL into the bag. It was then aligned with Rayner's suggested axis of placement. All viscoelastic was removed, and a single 10-0 nylon suture was used to secure the main incision to minimize the risk of postoperative rotation of the lens. Postoperatively, all patients received a 3 -week course of dexamethasone $0.1 \%$ and chloramphenicol drops. The corneal suture was removed at 2 weeks under topical anesthetic. The axis of alignment was confirmed to be correct at the slit lamp but not formally measured.

The preoperative data recorded included age, sex, laterality, surgeon (trainee vs consultant), comorbidity, keratometry, and subjective refraction. The operative data included occurrence of faulty capsulorrhexis and posterior capsular rupture. The postoperative data were collected at the final follow-up 3 months after surgery and included unaided visual acuities (UAVAs) and subjective refraction.

All data were entered into Microsoft Excel. Astigmatic values were converted to power vectors based on Thibos' method. ${ }^{8}$ In his analysis of astigmatism, 3 values were created to represent a meridian and an axis as a single value in 3-dimensional space. Value $\mathrm{M}$ corresponds to the spherical equivalent of the refractive error, while $J_{0}$ and $J_{45}$ represent the magnitude and 
direction of the cylinder in 2 axes: one at $0^{\circ}$ and another at $45^{\circ}$. Every refraction becomes a unique combination of values, which can be plotted in 3-dimensional space. Statistics were performed using SPSS 17.0 (SPSS Inc; Chicago, Illinois, USA). Continuous variables were assessed using Student paired $t$ test with $P<0.05$ considered to be significant.

\section{Results}

A total of 46 eyes from 34 patients underwent T-IOL implantation. Of 46 eyes, 24 belonged to male patients, and 22 were right eyes. The mean age of the population was 66.68 $( \pm 12.4)$ years, consistent with a normal cataract population. Over 35 operations were performed by a consultant (CKP), and the remaining were performed by a junior trainee, using the same method, under supervision by CKP. There were no operative complications.

\section{Comorbidity}

The majority of eyes (33/46) did not have any ocular comorbidity. The high incidence of previous retinal detachment surgery $(n=6$ eyes) and retinopathy of prematurity $(n=2$ eyes) reflects the author's (CKP) vitreoretinal practice. Remaining comorbidities include corneal scarring ( $\mathrm{n}=2$ eyes), ocular hypertension, early dry age-related macular degeneration, and optic neuropathy (all $n=1$ eye).

\section{Refraction}

The preoperative corneal astigmatism was compared with the postoperative refractive astigmatism. For the purpose of vector analysis, all the cylinders were first converted to plus cylinders by transposition. Then, they were converted to power vectors using the following formulae: $J_{0}=(-\mathrm{c} / 2)$ $\cos 2 \alpha$ and $J_{45}=(-\mathrm{c} / 2) \sin 2 \alpha$, where $\alpha$ is the axis of the cylinder, and $\mathrm{c}$ is the cylinder magnitude. ${ }^{8}$ They were compared by applying Student paired $t$ test.

The difference in magnitude between preoperative and postoperative $J_{0}$ was highly significant. The difference in magnitude between preoperative and postoperative $J_{45}$ was not statistically significant because the majority of the patients have no oblique astigmatism. The value of $J_{45}$ was therefore close to zero in both groups (Table 1). When viewed graphically, the astigmatism clusters around the origin postoperatively show a reduction in magnitude (Figure 2 ).

The post-operative cylinder shows that the vast majority of patients require $<1 \mathrm{D}$ of postoperative cylinder, with outliers requiring $>2 \mathrm{D}$ of cylinder. It is possible to see in Figure 2 an outlier patient whose lens was not correctly aligned. Preoperatively, the patient's cylinder
Table I Power vectors analyzed preoperatively and postoperatively with paired sample $t$ test used to calculate $P$ values

\begin{tabular}{llll}
\hline & $\begin{array}{l}\text { Preoperative } \\
\text { keratometric } \\
\text { cylinder }\end{array}$ & $\begin{array}{l}\text { Postoperative } \\
\text { refractive } \\
\text { cylinder }\end{array}$ & P value \\
\hline$J_{0}$ (D) & $-0.81 \pm 0.85$ & $0.09 \pm 0.42$ & $<0.0001$ \\
$J_{45}$ (D) & $-0.06 \pm 0.57$ & $-0.05 \pm 0.36$ & 0.9417 \\
\hline
\end{tabular}

measured $-4.5 \mathrm{D}$, whereas postoperatively, it was $-5 \mathrm{D}$ due to misalignment of the lens. Rotation of the lens, as a secondary procedure, was declined by the patient. Preoperatively, $77.6 \%$ of patients had $>1.5 \mathrm{D}$ astigmatism, compared with $6.9 \%$ postoperatively.

\section{Visual acuity}

Postoperative UAVAs are shown in Figure 3. Nearly, 50\% of patients were able to see $6 / 6$ or better, unaided, while $72 \%$ achieved 6/9, well within British driving standard. Of the patients who had visual acuities of $6 / 18$ or worse postoperatively, corrected vision had been poor preoperatively secondary to a retinal detachment repair $(n=1)$ and corneal scarring $(n=1)$. A patient with UAVA of $6 / 24$ postoperatively was able to see $6 / 6$ with spectacle correction. This patient had misalignment of lens and therefore had uncorrected astigmatism of $-5 \mathrm{D}$.

\section{Percentage change of cylinder}

As seen in Alcon's evaluation of the Acrysof Toric lens, the percentage change of cylinder helps to calculate the residual postoperative cylinder as a percentage of the preoperative cylinder. ${ }^{7}$ A $100 \%$ change, by definition, means that the cylinder has been completely corrected, whereas a negative percentage shows the astigmatism has increased in power. These results can therefore be directly compared with Alcon's data. By separating the patients by their initial preoperative cylinder, it is noted that more reliable results are gained at higher powers of cylinder (Table 2).

\section{Discussion}

T-IOLs have gained a reputation for reliable correction of moderate to high astigmatism. Their effective correction of astigmatism relies on accurate keratometry, choice of appropriate lens, and perfect insertion technique with no postoperative rotation. Any misalignment should be recognized early in order to allow surgical correction if required.

Accurate biometry is essential for any cataract surgery. A variation of $100 \mu \mathrm{m}$ in axial length translates to $0.28 \mathrm{D}$ of variation in the chosen power of spherical lens. ${ }^{9}$ Keratometry 

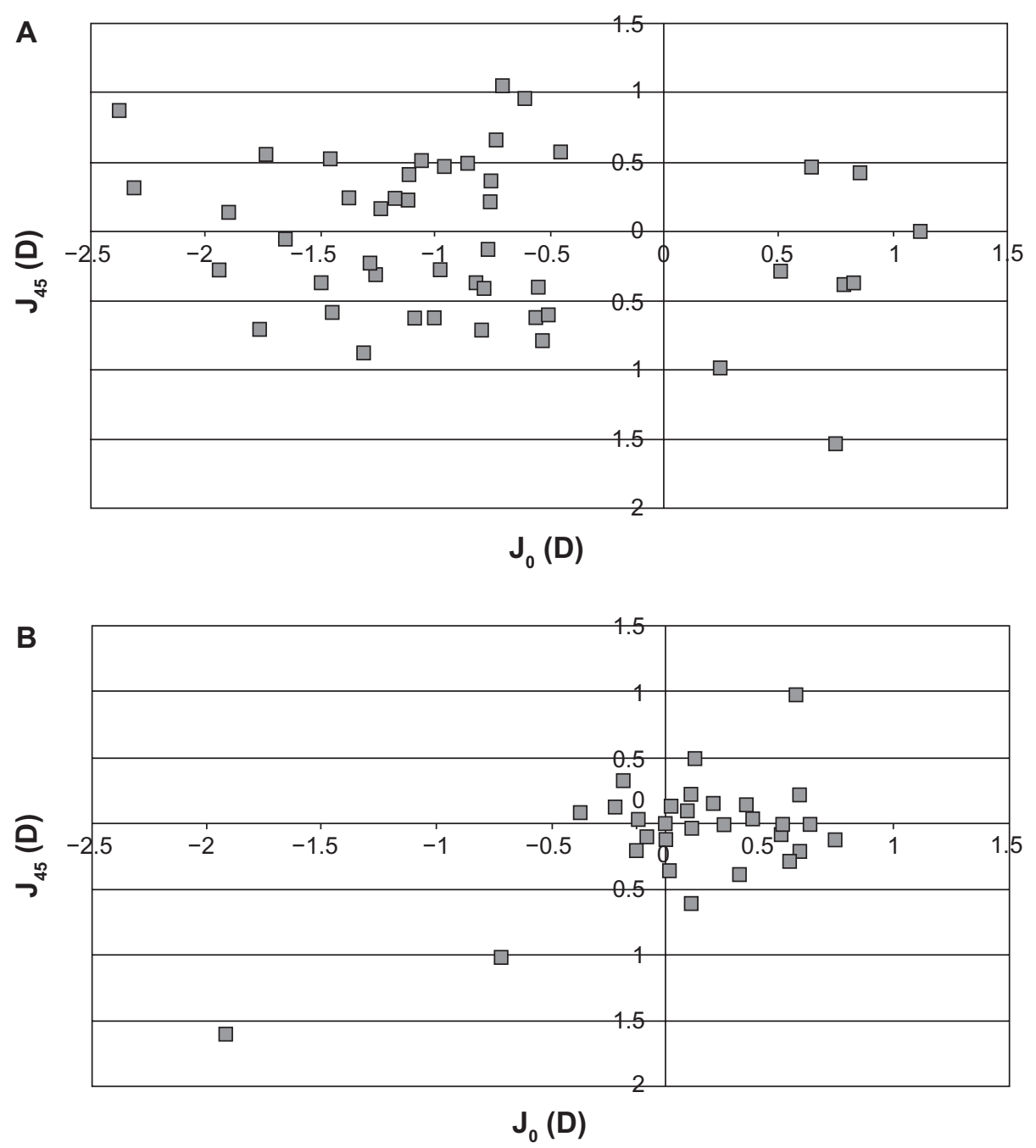

Figure 2 A) Preoperative keratometric cylinder where each square represents a single eye. B) Postoperative refractive cylinder where 13 patients are represented by the single square that sits on the origin.

must be accurate, not only because calculations of sphere and cylinder powers are made from the data but also axis of lens placement is calculated from the information. When taking serial fundus photographs, Viestenz et $\mathrm{al}^{10}$ documented that rotation (or torsion) of an eye by $3^{\circ}$ was present in $36 \%$ of patients. The most marked rotation was $11.5^{\circ}$. Therefore, the axis designated to the cornea by a computerized keratometer may not necessarily be truly on-axis. In our department, Zeiss IOL Master is considered to be the gold standard for keratometry. All of our operators are highly trained staff who ensure the patient is positioned appropriately prior to taking measurements.

All our statistics are based on preoperative keratometric and postoperative refractive astigmatism. Preoperative refraction measures both corneal and lenticular astigmatism, whereas postoperative refraction measures the corneal astigmatism and a contribution from the intraocular lens.
Preoperative keratometry separates the corneal and lenticular elements of astigmatism. In a well-designed prospective study, every patient would have preoperative corneal topography performed in order to detect any subtle corneal irregularities. Due to the retrospective nature of our paper, this has unfortunately not been performed.

Each lens was chosen using the online Rayner T-IOL calculator, Raytrace. Insertion of keratometric data and desired postoperative spherical equivalence produce a selection of appropriate lenses. Surgically-induced astigmatism (SIA) may be factored into the lens choice. In our case series, SIA was not entered into the calculations. Hill ${ }^{11}$ concludes that failing to account for SIA, when calculating Acrysof T-IOL power, results in choosing the incorrect lens on $51 \%$ of occasions in temporal incisions vs $44 \%$ in superior incisions. At the time of writing, Acrysof lenses are only available in 3 cylindrical powers $(\mathrm{T} 3=1.5 \mathrm{D}, \mathrm{T} 4=2.25 \mathrm{D}$, 


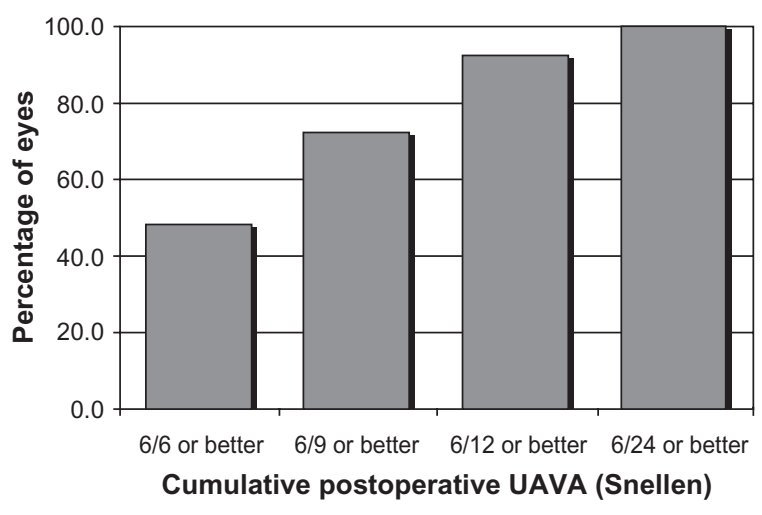

Figure 3 Unaided Snellen Visual Acuity measured 3 months after surgery.

and T5 $=3.0 \mathrm{D}$ ), where an error in lens calculation encounters a $0.75 \mathrm{D}$ step in cylindrical power.

In our series of patients, the Rayner lens was inserted using a single-use injector through a $3-\mathrm{mm}$ wound. Wound length and construction are known to play an important role in postoperative corneal astigmatism with shorter wounds having less astigmatic influence than longer wounds. ${ }^{2,3}$ At the time of writing, Rayner T-flex lens can only be injected through a wound $>3 \mathrm{~mm}$ in length. This audit was performed retrospectively in a routine clinical practice where corneal topography is not measured prior to cataract surgery. To refine our surgical outcomes, it would be necessary to measure corneal topography both preoperatively and postoperatively to adjust for SIA.

Preoperative marking of the cornea must be performed when the patient is positioned vertically to avoid cyclotorsion while recumbent. Despite this, it is possible that small degrees of error may be incurred at this stage of the procedure. Methods of marking the cornea during surgery and insertion techniques have been published, aiming to minimize any further error. ${ }^{12,13}$ Similarly, removal of the viscoelastic is imperative to prevent postoperative rotation within the bag, before capsular contraction occurs.

It is well known that with every degree of rotation off the axis of alignment, a toric lens loses $3.3 \%$ of its astigmatic power. With $30^{\circ}$ of rotation, the toric power is lost in its entirety. ${ }^{14}$ Rotational stability of this lens has not been formally

Table 2 Residual postoperative cylinder calculated as a percentage of the preoperative cylinder

\begin{tabular}{lllll}
\hline $\begin{array}{l}\text { Preoperative } \\
\text { cylinder }\end{array}$ & $\begin{array}{l}\text { Sample } \\
\text { size }\end{array}$ & $\begin{array}{l}\text { Mean \% } \\
\text { change }\end{array}$ & $\begin{array}{l}\text { Minimum \% } \\
\text { change }\end{array}$ & $\begin{array}{l}\text { Maximum \% } \\
\text { change }\end{array}$ \\
\hline <I.5 D & 13 & $30 \pm 53$ & -66 & 100 \\
I.5-2 D & 7 & $75 \pm 26$ & 25 & 100 \\
$\geq 2$ D & 26 & $79 \pm 29$ & -11 & 100 \\
\hline
\end{tabular}

studied in this article. However, within our case series, it is possible to show how the benefits of the toric element of the lens can be lost, either through surgical inaccuracies or secondary to postoperative rotation. Chang ${ }^{15}$ suggests that postoperative rotation of the lens is more likely in myopic eyes or those patients with larger diameter capsular bags. Our outlier patient (Figure 2) had no benefit from the toric element of his lens due to postoperative rotation. He had a spherical equivalent of $-7.25 \mathrm{D}$ preoperatively; this may have contributed to his poor IOL alignment postoperatively. The correction of misalignment of the lens, as a secondary procedure, should be consented for in T-IOL patients, in addition to standard cataract surgery risks.

Regular bow-tie astigmatism will be corrected in a more predictable manner than in patients with corneal scarring or irregular astigmatism. Our case series excluded patients with irregular astigmatism, previous corneal grafts, or keratoconus to reduce outlier bias. Despite their exclusion from this study, Rayner lenses have been licensed for use in patients with high degrees of astigmatism and previous corneal grafts. Our clinical experience, although unreported, confirms their success in this specific group of patients. There is no current evidence base to support their use in these groups of patients.

Despite potential areas for inaccuracies, our results show that the Rayner T-flex T-IOL can be used successfully in routine practice in patients with astigmatism. Nearly, $75 \%$ of our patients were able to achieve the British driving standard with their postoperative uncorrected vision. We were also able to reduce astigmatism $>1.5 \mathrm{D}$ from $77 \%$ pre-operatively to $7 \%$ with insertion of a T-IOL.

Despite our small sample size, we were able to produce our results more consistently in patients who had larger initial astigmatism, confirming previous suggestions that T-IOLs can be used in patients with $>2 \mathrm{D}$ astigmatism. ${ }^{4}$ Newer techniques for confirming the axis of astigmatism, such as iris fingerprinting and intraoperative wavefront aberrometry, offer scope for further improvement in refractive outcome with T-IOLs. ${ }^{16,17}$ In conclusion, Rayner lenses offer a simple but effective solution to the treatment of corneal astigmatism in patients undergoing cataract surgery.

\section{Disclosure}

The authors report no conflicts of interest in this work.

\section{References}

1. Hoffer KJ. Biometry of 7,500 cataractous eyes [correction 890]. Am J Ophthalmol. 1980;90:360-368.

2. Masket S, Wang L, Belani S. Induced astigmatism with 2.2- and 3.0-mm coaxial phacoemulsification incisions. J Refract Surg. 2009;25(1):21-24. 
3. Wang J, Zhang EK, Fan WY, Ma JX, Zhao PF. The effect of micro-incision and small-incision coaxial phaco-emulsification on corneal astigmatism. Clin Experiment Ophthalmol. 2009;37(7):664-669.

4. Amesbury EC, Miller KM. Correction of astigmatism at the time of cataract surgery. Curr Opin Ophthalmol. 2009;20(1):19-24.

5. Sun X, Vicary D, Montgomery P, Griffiths M. Toric intraocular lenses for correcting astigmatism in 130 eyes. Ophthalmology. 2000;107(9): $1776-1782$.

6. Mendicute J, Irigoyen C, Ruiz M, Illarramendi I, Ferrer-Blasco T, Montés-Micó R. Toric intraocular lens versus opposite clear corneal incisions to correct astigmatism in eyes having cataract surgery. $J$ Cataract Refract Surg. 2009;35(3):451-458.

7. Lane SS. The Acrysof Toric IOL's FDA Trial results: a look at the clinical data. Cataract and Refractive Surgery Today. May, 2006:66-68.

8. Thibos LN, Horner OD. Power vector analysis of the optical outcome of refractive surgery. J Cataract Refract Surg. 2001;27(1):80-85.

9. Olsen T. Theoretical approach to intraocular lens calculation using Gaussian optics. J Cataract Refract Surg. 1987;13(2):141-145.

10. Viestenz A, Seitz B, Langenbucher A. Evaluating the eye's rotational stability during standard photography: effect on determining the axial orientation of toric intraocular lenses. J Cataract Refract Surg. 2005; 31(3):557-561.
11. Hill W. Expected effects of surgically induced astigmatism on AcrySof toric intraocular lens results. J Cataract Refract Surg. 2008;34(3): 364-367.

12. Ma JJK, Tseng SS. Simple method for accurate alignment in toric phakic and aphakic intraocular lens implantation. $J$ Cataract Refract Surg. 2008;34(10):1631-1636.

13. Graether JM. Simplified system of marking the cornea for a toric intraocular lens. J Cataract Refract Surg. 2009;35(9):1498-1500.

14. Novis C. Astigmatism and toric intraocular lenses. Curr Opin Ophthalmol. 2000;11(1):47-50.

15. Chang DF. Repositioning technique and rate for toric intraocular lenses. J Cataract Refract Surg. 2009;35(7):1315-1316.

16. Osher RH. Iris fingerprinting: new method for improving accuracy in toric lens orientation. J Cataract Refract Surg. 2010;36:351-352.

17. Gualdi L, Cappello V, Giordano C. The use of NIDEK OPD Scan II wavefront aberrometry in toric intraocular lens implantation. J Refract Surg. 2009;25 Suppl 1:S110-S115.
Clinical Optometry

\section{Publish your work in this journal}

Clinical Optometry is an international, peer-reviewed, open access journal publishing original research, basic science, clinical and epidemiological studies, reviews and evaluations on clinical optometry. All aspects of patient care are addressed within the journal as well as the practice of optometry including economic and business analyses. Basic and clinical

\section{Dovepress}

research papers are published that cover all aspects of optics, refraction and its application to the theory and practice of optometry. The manuscript management system is completely online and includes a very quick and fair peer-review system, which is all easy to use. Visit http://www.dovepress. com/testimonials.php to read real quotes from published authors. 